\title{
Design of high-rise dwelling houses for Ho Chi Minh City within the framework of the "smart city" concept
}

\author{
Nguyen Hong Loan ${ }^{1, *}$, Nguyen Van Tin ${ }^{1}$ \\ ${ }^{1}$ University of Architecture Ho Chi Minh City, 196 Pasteur, District 3, Ho Chi Minh City, 700000, \\ Vietnam
}

\begin{abstract}
There are differences in the concepts of smart cities, which are reflected in many ideas and solutions. Globally one of the similarities of the goals for achieving smart cities is sustainable developmentwith the provision of best living conditions for people beingthe first priority. Ho Chi Minh City is not out of trend, taking the planning steps for the goal of becoming a smart city. It is necessary that design and construction of high-rise dwelling houses meet the criteria of "smart city" concept. This paper explores the design of high-rise dwelling houses forHo Chi Minh City with regards tothe framework of "smart city" concept. Methods used in the paper includedata collection, analytical - synthetical and modeling method.In order to proposedesign tasks and solutions of high-rise dwelling houses forHo Chi Minh Cityinthe concept "smart city"in the current period and near future, we present new approach, whichcan alsobe applied in practice for different cities in Vietnam.Moveover, it can also establishinformation resources, which areuseful in connecting and promotingfurther development for the success of a "smart city" program.
\end{abstract}

\section{Introduction}

Smart city is a new concept of urbanization in the world. Many studies have demonstrated thatdefinitions of "smart city" show differences in approach, scale and performing steps in various territories. Through review of the studies, there were somesimilarities of the criteria of a smart city. A development process of a "smart city" needs to be organized, designed and built in successionto ensure its success [1].

Vietnam has been under a comprehensive change with rapid urbanization. There are many studiesfrom the government and experts to provide solutions for the successful implementation of urbanization. Although the current condition in Ho Chi Minh City has some cons in terms of infrastructure, urban planning, energy, living quality, etc., it also has a lot of potential to become a smart city in the future. This could be explained by the viewpoint "smart city concept can be used for transforming any city into a smart city. Smart city has various overwhelming benefits and it a win - win situation for both, government and the citizens" [2].

\footnotetext{
*Corrwsponding author: loanru@mail.ru
} 
Those studies showed that the concept and criteria for a smart city are very diverse.However, by reviewing the world experiences and practicalconditions ofHo Chi Minh City, the followingmissions can be proposed to convertHo Chi Minh City into a smart city: (1) to develop and improve infrastructure; (2) to ensure the best living conditions for citizens; and (3) to build basis for implementingprogram of a smart city in the future. Toachieve these goals, there should be a concerted participation of many different areas, subjects and levels, where the role of people will be the key to the success. This can be done in a variety of ways depending on the actual conditions and capabilities of the participants, where good living conditions will always be a top priority.

This paper demonstrates thathigh-rise dwelling houses havemany advantages in addressing problems of housing demand in Ho Chi Minh City with the new missions. The objectives of this paper areto build design tasks and to propose design solutions for high-rise dwelling houses in Ho Chi Minh City within the framework of "smart city" concept. The ability to apply new design solutions of this study plays a vital role in addressing people's living needs. The requirements of comfort, safety, humanity and sustainability of living space in the high-rise condominiums will be met.In addition, its results can also contribute to build a "smart city" program forHo Chi Minh City and other cities of Vietnam.

\section{Literature review}

There are many different definitions of smart cities. For example, in 2014 International Telecommunication Union found out over 100 definitions of smart cities[3]. The most common definition of "smart city" is "the effective integration of physical, digital and human systems in the built environment to deliver sustainable, prosperous and inclusive future of its citizens" [2]. Through the review of scientific papers and reports six components of a smart city are drawn, including: smart governance, smart economic, smart mobility, smart environment, smart people and smart living [2-9]. It was presented in"Research report on Smart City"by Government of Hong Kong.In content of the smart environment, the requirements for resource management, urban planning and smart buildingswere set [9].

In the paper "Smart city in Europe" of the3rd Central European Conference in Regional Science - CERS 2009, the author focused"on the role of infrastructure, although much research has also been carried out on the role of human capital/education, social and relational capital and environmental interest as important drivers of urban growth"[10]. The report of the United Nationsat the Eighteenth Session in May 2016, presented by Commission on Science and Technology for Development, mentioned key urbanization trends and their links to the 2030 Agenda Sustainable Development.Thisreport identified opportunities and challenges for the different cities when implementing the program urbanization. For developing countries, a complete infrastructure system is in immediate need. The role of infrastructure is defined as "smart infrastructure provides the foundation for all of the key themes related to a smart city, including smart people, smart mobility, smart economy, smart living, smart governance and smart environment" [3].

The deployment of the smart city program in the world had many challenges, including the problem of abusing of technology which causes incompatibility in harmony with human life. In June 2015, the Government of India developed the program "100 smart cities" that aimed to improve the quality of life for its citizens [11]. This program was built in 5-year period, which emphasizedthe role of government and civil society. Many challenges were set out in this process, in which the development and improvement of infrastructure played an important role. The paper "Evaluating the need for smart cities in India" have been pointed out the current conditions and causes of incompletion in cities. The simultaneousdevelopment of all areashassynchronously created prosperity for citizens [4]. Taking the urban planning in Singapore as an example, it setted up four basic missions 
including smart environment, smart life, smart service and smart urban planning to satisfy the requirements in comfort, efficiency, safety and sustainability [12].

In addition, in the report "Smart cities in Italy", the author emphasized: "Smart cities offer revolutionary opportunities for economic, social and technological change". The author also listed several definitions of smart city and pointed out that "a smart city is a sustainable city - for everyone" and "the only unifying factor seems to be the concept of sustainability" [1].

The world's urbanization hasalready been underway with $66 \%$ of the population expected to live in urban areas by 2050, in which population will be mainly concentrated in Africa, Asia and Latin America [13, 14]. The development context of cities in Vietnam is reflected by a rapid urbanization (approximately $3 \%$ per year) witha low starting point. Vietnam still has many opportunities for new construction because it is only the half way through urbanization [15]. Ho Chi Minh City is the largest city in Vietnam with a population of about 10 million andapproximately 3 million immigrants. GDP per capita in Hochiminh City is the highest in the country, about 5500USD/year, which accounts for $30 \%$ of the country[16]. By statistics, by 2035 the city will be expanded to a metropolitan area equivalent to a population of 26 million. This issue possibly poses many challenges to the government and its citizens.

Socio-economic factors have been the barriers to many solutions in the implementation of urban development strategies for Ho Chi Minh City. According to Vietnamese architectural experts and sociologists, there is a need for a new governance approach with the aim of coordination between human capital, social capital and technological strength to create a better and more sustainable life.The Government of Ho Chi Minh City has planned to build thecity to become a smart city by 2025 to promote economic development and improve the quality of living environment and service forcitizens[17].During the project, many seminars and cooperation agreements have been organized. "Smart city must be based on the technology development with the human factor as a focal point and the solution is build a modern city with safety and healthy in sustainable development" a Microsoft Corporation's delegate mentioned in one of the seminars[18].

However, there have not been studies in designing of high-rise dwelling houses in "smart city" concept for Ho Chi Minh City. Current proposalshave focused to mobility, grid power, communication, water supply and drainage system, ecology and governance. The implementing programsneedmore participation from experts and citizens.This also contributes to the evaluation of the program's effectiveness and feasibility, as well as to the determining of future plan.

In terms of the natural and climate conditions of Vietnam, especially in Ho Chi Minh city, there is a high requirement for ventilation and heat insulation for buildings. The architectural and technical solutions for high-rise dwelling houses are based on a combination of traditional architectural values and modern options [19]. Compliance with environmental parameters of microclimate by means of costly structures and materials or the use of energyintensive equipment is not recommended [20].For example, Niu specifiedmain issues of designing of high-rise condominiums to ensure the best microclimate in living environment for the users[21]. The experience of designing, constructing and operating high-rise dwelling houses in Singapore demonstrates the success of the projects to ensure the living conditions of citizens. Generalove and Generalov identified six typical operational planning diagrams of high-rise dwelling housesin Singapore, which can be considered for Hochiminh City[22].

By statistics of Department of Constructionof Ho Chi Minh City, there are about 500 thousandsof households do not have their own houses, 300 thousandsneed to rent apartments and 143 thousand need to buy condominiums or houses. About the structure of condominiums in the real estate marketin Vietnam, by reports CBRE Co. Ltd., in 2016 the investors focus on providing the middle class wih three types of products: Type A (1 bedroom) $45-65 \mathrm{~m}^{2}$ with the rate of 10-20\%; Type B ( 2 bedrooms) $70-90 \mathrm{~m}^{2}$ with the rate of $50-60 \%$; Type C (3 bedrooms) $95-120 \mathrm{~m}^{2}$ with the rate of $10-30 \%$. It reflects the market 
demand and the ability to meet the living conditions of different types of condominiums. Besides, there are special condominiums offered by high-quality projects within the city center: Studio, Loft, Duplex and Penthouse with the rate of 5-10\% [23]. The growth of new types specifically has represented the change of the market, the trust and favourite of citizens. In general, it will encourage the propose of smart solutions in the building and completeness the infrastructure in a smart way.

The studyof Le Van Dung researched the living environment in urban residences in Vietnam and the ability to improve the quality of comfort and health in three levels: apartment, building and residential area. The author presented the concept and principle of the intergrated model of comfort in high-rise dwelling housesfor conditions of urban Vietnam. Directionfor developmentand improvement the quality of life was proposed for more comfortable and smarter in the future [24].Another issue of designing of condominiums issolvethe needs for privacy and comfort in living environment, particularly in tropical and sub-tropical climates, where design solutions for microclimate conditions, can strongly affect the organization of living spaces. This issue was considered in the paper by Rosemary Kennedy, Laurie Buys and Evonne Miller as an example of approach and solve the problem in other areas such as Ho Chi Minh City [25].

By experiences, electricity is considered the main source of energy and will continue playing a key role in smart cities: "no electricity, no smart city" [13]. Vietnam has achieved some remarkable results in bringing green technology into construction works. Technological solutions which focus on the green energy (solar and wind energy), unbaked materials, technology saving and filtration water for reuse, etc could participate in the operation of the buildings step by step in order to advance the living condition [26]. Smart management and engineering technologyhavebeen chosen for different projects, for example, BMS/BASBuilding Management System/Building Automation System-has beenused in the integration of building systems to manage the engineering and automatical systems[27].In addition, design requirements for urban planning, fire protection system, standards of microclimate and guidelines for encouraging the use of energy-efficient materials are widely disseminated and implemented effectively through the formalities permission of the project.

Theapplication of green building rating systems has been implemented in many countries with different views and aspects of preference. Vietnam has released own green building rating system - Lotus.It is a set of market-based green building rating tools developed by the Vietnam Green Building Council specifically for construction in Vietnam. Rating systemLotus has been developed through long-term research, with the expert advice of specialists giving particular consideration to Vietnam's economic and natural characteristics and to existing Vietnamese standards and policies [28].The criteria of system Lotus are considered appropriate for the organization and formation of smart cities in the future.

In the program of sustainable development, there are many workshops and studies to provide direction for managers and designers, contributing to encouraging people and investors to build modern, efficient and national architecture. In declaration "Green Architecture of Vietnam", published on 27 April 2011, Vietnam Architects Association issued five criteria [29]: (1) sustainable location; (2) use resources and energy efficiently; (3) the quality of microclimate in the building; (4) advance and identityof architecture; (5) sustainability of society and humanity.

In the aspect of tradition and culture in architecture, especially in architecture of housing in new design and construction, there are many assertions by experts. For example, "for achievement of architectural identity, modern Vietnamese architecture must ensure technical and cultural sustainability. It should research into the root source of traditional architecture, which is appropriate for the policies, so new architectural spaces are formed in a dynamic and attractive environment in terms of tradition and culture"[30].In addition, trends and solutions for the development of new urban centers for Ho Chi Minh City must be 
promotedspecific cultural values of urban architecture[31].Nguyen Song Hoang Nguyen provided many diagrams and conclusions about the traditional cultural values that can be exploited and promoted for the architecture of urban residence. The author proposed to build models and methods of exploiting the value of culture in the architecture of dwelling houses[32].

\section{3 materials and methods}

The paper was organizedin a logical order with references to different scientific papers, reports and opinions of experts. Common assertions and trends were emphasized. The main ideas and scientific bases were guided to increase access to the author's suggestions and conclusions. Methodsused in the paper include as follows:

Data collection method: Reviewscientific papers on the theme "smart city" to give a general viewwhich is the basis for determining the direction of the article.Determinationof general criteria in "smart city" concept is important. The views and experiences of implementing program of a smart city in developing countries and in the territories with natural and historical similarities with Ho Chi Minh City were thoroughly studied.

Urbanization trends in the world and Vietnam were studied to provide appropriate conclusions to Vietnam in the current period and near future. The actual conditions of Ho Chi Minh City were updated and reviewed. The main aspects of interest were (1) urbanization trend of the city, (2) socio-economic conditions, and (3) requirements of the climate in architecture. In addition, information on the apartment market and users' demand was listed to ensure the actualization of the proposed solutions. Condominiums have considered as the new for whole Vietnamese, so their design, construction and operation should be realized with experiences from other countries, especially from territories with similar conditions with Ho Chi Minh City. The important aspects are asfollows: implementation at different stages of each project and housing program, design goals, users' request, design standards, feasibility of solutions. General tendencies and perspectives of sustainable architecture were studied for the designing of high-rise dwelling houses in Ho Chi Minh City. In addition, new solutions in the direction of smart operation were identified.

Analytical - synthetical method: The collected information was analyzed and synthesized to clarify the ideas, perspectives and practical experiences. "Smart city" concept has been new for Vietnam, so the chosen informattion is analysed to identify general criteria of a smart city in the world, that can be basic for Vietnam. Real conditions in Ho Chi Minh City were analysed and synthesized with regards to the current and future demands of citizens. In addition, information on the current state of urban planning and architecture was analyzed to address their strengths and weaknesses, particularly the types of housing such as townhouses and high-rise condominiums. These specific types of housing in urban Vietnamwere compared, in that had been shown many advantages of high-rise dwelling houses in the program ofturnning Ho Chi Minh City into a smart city. Aspects, which effect to the design of high-rise dwelling houses were considered to ensure the success of project and the "smart city" program.

Modeling method: A colorful diagram was used to show causal links between the main contents of this article.

\section{Results}

The trend of high-rise dwelling design to convert Ho Chi Minh City to a smart city is based on theoretical and practical evidences. Relevant aspects are presented as following:(1) the actual conditions of Ho Chi Minh City; (2) the requirements of a successful real estate project, 
(3) the requirements of sustainable development; (4) preparation for smart operation and management; (5) forecast for steps toward smart city improvement.

Aspects of a project of high-rise dwelling housesin Ho Chi Minh City within the framework of the "smart city" conceptare recommended: (1) urban planning; (2) architectureinterior; (3) structure and system mechanical, electrical andplumbing (MEP); (4)sustainable development. These factors play an important role in the success of a project, demonstrating the combinationin large-scale housing projects. It meets the needs of users in the direction of more comfortable and smarter. Moreover, it acts as a stepping stonefor the next steps of the "smart city" program.

Their characteristics can be shownin follows:

(1) urban planning: it is the weakness of the status of urban Vietnam, such as: high construction density, small area of sites, low proportion of green and traffic area, and facilities do not meet the needs of modern life;

(2) architecture- interior: the structure of apartments is an important problem of any project. The structure and layout must be reasonable to meet market demand on the basis of ensuring the architectural and interior design standards. These criteria should be implemented at a higher level and more flexible, meeting the requirements of living environment in the current period and near future;

(3) structure and system MEP:technical issues affect the safety and economic problems of the project. Flexibility in planing of architectural spaces and convenience in the use of interior spaces must be emphasized. New smart technological solutions should be applied in accordance withthe staged division of program "smart city";

(4) sustainable development: in the context of rapid urbanization and economic development of Vietnam sustainable development is necessary. Demand for specific culture and traditional values has been one of interest from citizens and experts. It is important to put them in housing architecture, especially high-rise dwelling houses, which are a modern type of housing for most Vietnamese people. It answers the question of people's attachment to the living environment, enabling smart solutions to be realized and replicated.

Design tasks for high-rise dwelling housesin Ho Chi Minh City within the framework of the "smart city" concept are divided according to the mentioned aspects so as to facilitate the approach of design solutions.

Table 1. Design tasks for high-rise dwelling houses in Ho Chi Minh City within the framework of the "smart city" concept.

\begin{tabular}{|c|c|}
\hline Aspects & Design tasks \\
\hline $\begin{array}{c}\text { Urban } \\
\text { planning }\end{array}$ & $\begin{array}{l}\text { - Identify convenient areas and locations for high-rise dwelling houses. } \\
\text { - Determine suitabilityof parameters of urban planning and architecture for } \\
\text { high-rise dwelling houses in the direction of smartcity. }\end{array}$ \\
\hline $\begin{array}{l}\text { Architecture } \\
\text { - Interior }\end{array}$ & $\begin{array}{l}\text { - Ensurethe structure of the apartments inthe efficiency of business } \\
\text { management. } \\
\text { - Improve the quality of the residential area through the general plan. } \\
\text { - Enhance the area, quantity and quality of facilities in the buildings. } \\
\text { - Ensure the microclimate conditions in the residential areasand in each } \\
\text { interior space. }\end{array}$ \\
\hline $\begin{array}{l}\text { Structure } \\
\text { and system } \\
\text { MEP }\end{array}$ & $\begin{array}{l}\text { - Enhance efficiency, economy and safety. } \\
\text { - Ensure the convenience in the layout and reconstruction for the future. } \\
\text { - Apply smart solutions for operation and maintenance of buildings. }\end{array}$ \\
\hline $\begin{array}{l}\text { Sustainable } \\
\text { development }\end{array}$ & $\begin{array}{l}\text { - Ensure the criteria of sustainable architecture, which has been applied in } \\
\text { Vietnam. } \\
\text { - Meet the requirements of regional architectural identity and promote specific } \\
\text { cultural values. }\end{array}$ \\
\hline
\end{tabular}


\begin{tabular}{|l|l|}
\hline Apply technological solutions for operation and maintenance of buildings in \\
the smart direction.
\end{tabular}

The proposed design solutions are based on the principles of designing of high-rise dwelling house. In addition, in view of "smart city" conceptthey must focus on improving the quality of living space, utility space, comfort and the smart solution. The design solutions must ensure the ability to perform under the actual conditions in Ho Chi Minh City in the current period and near future. Based on the recommendations of this paper, more sensible and smart proposals for high-rise dwelling house will be realized in the future when practical conditions will be met.

Table 2. Design solutions for high-rise dwelling houses in Ho Chi Minh Citywithin the framework of the "smart city" concept.

\begin{tabular}{|c|c|}
\hline Aspects & Design solutions \\
\hline $\begin{array}{c}\text { Urban } \\
\text { planning }\end{array}$ & $\begin{array}{l}\text { - The role of location must beshown in the ensuring convenient access and } \\
\text { effective infrastructure connection. } \\
\text { - Reasonable functional areas of facilities in daily activities of citizens are } \\
\text { appropriately determined. } \\
\text { - Density and land use of constructionmust beeffectivecoefficient. }\end{array}$ \\
\hline $\begin{array}{l}\text { Architecture } \\
\text { - Interior }\end{array}$ & $\begin{array}{l}\text { - Utilities and living environment are ensured through solutions on functional } \\
\text { plan and operation management. } \\
\text { - The structure of apartments is divided by market segment and level of } \\
\text { investment to ensure the rationalityin the combination of following factors: } \\
\text { standard area, comfort, health and cost. } \\
\text { - The microclimate conditions in the residential areas and in each interior } \\
\text { space are ensuredthrough the solutions of functional areas, form and } \\
\text { enclosure. }\end{array}$ \\
\hline $\begin{array}{l}\text { Structure } \\
\text { and system } \\
\text { MEP }\end{array}$ & $\begin{array}{l}\text { - Structural solutions, which are appropriate to the architecture of the building } \\
\text { must been selectedin the calculation of economic and safety factors. } \\
\text { - Solutions of structural model can provide appropriate columnar steps for plan } \\
\text { and flexibility in each binding position. } \\
\text { - SystemMEP must be built in a large scale for serving community groups with } \\
\text { long term effectiveness. } \\
\text { - The ability to link and update technology will be ensured in different stages } \\
\text { of development. } \\
\text { - It is necessary to apply smart operation and maintenance solutions in each } \\
\text { stage, especially in the current period couldbe thought of smart solutions as } \\
\text { BMS, BAS, etc. } \\
\text { - It is recommended toapply solutions for connecting the technical system of } \\
\text { operation of the building, connectproject to the general infrastructure, build } \\
\text { database sources, create the premise for the future "Internet of Things" } \\
\text { system. } \\
\text { - Smart operational models for each apartment or building can be proposed, } \\
\text { for example: automatic control system, security system, air quality control } \\
\text { system, sensor system, etc. }\end{array}$ \\
\hline $\begin{array}{l}\text { Sustainable } \\
\text { development }\end{array}$ & $\begin{array}{l}\text { - Cultural values must be integrated into methods of spaces organization, } \\
\text { models of activity, solutions of forms and details, as well as in the } \\
\text { organization of small functional spaces in the interior. } \\
\text { - The core values of ethnic culture is identified and promoted to create an } \\
\text { identity. } \\
\text { - It is necessary todetermine solutions of energy saving through layout, forms, } \\
\text { structures and using energy-saving materials, etc. } \\
\text { - The role of using different types of clean energy sources such as solar and } \\
\text { wind energy, etc must be shown. }\end{array}$ \\
\hline
\end{tabular}




\begin{tabular}{|l|l|}
\hline - Water resources can be saved and utilized in combine architecture and \\
technology. \\
- It must be minimized impact on the surrounding environment. \\
- And it is necessary toimprove the quality of the environment and ecology.
\end{tabular}

\section{Discussion}

Application ofsmart city model to Ho Chi Minh Cityis very complex. Thiscity is the fastest growthof Vietnam's economic, thereforethe forecast, organization and implementation to the development stages of this citywill play an important role. The synchronous implementation of all items of the smart city development model could be considered prioritizing areas based on the following factors: (1) necessity; (2) actual demands; (3) ability to realize in stages; (4) the potential of update and synchronization with the general system of the smart city model in the implementation phases.

In addition, the experience of urban development in developing countries demonstrates many issues that need to be addressed. In building the program of organization and formation of smart city for Ho Chi Minh City, there are many criteria to be implemented and the focus is smart infrastructure. The solutions for renovation and development of urban planning and architecture of Ho Chi Minh City are considered and proposed by many experts and managers, in which the priority are developing infrastructure and construction modern buildings with large scale.In that picture, determining the imperative and long-term factors in organizing implementation of a smart city has a practical basis. It needs to be affirmed that the role of citizens is always concerned and enhanced in all urban development activities, reflecting the humanity and the tendency of sustainable development. The requirement to ensure the best living conditions with a modern, comfortable, safe and ecological living environment is a priority.

One of the most enormous problems of architecture in Vietnam is the poor management - the people build housesthemselves, the government only manages. That leaves the city incomplete and in chaos[30]. In that picture, townhouses with major proportions in area and quantity have shown many inadequacies. By statistics, amajority of residential areas in Vietnam has beenlocatedin townhouses. The characteristics of the urban planning and architecture of townhouses in terms of comfort, efficiency, safety and sustainability spesify many disadvantages such as: (1) each household builds and uses a house on its own site, that splits the land into small lots and put high pressure on the infrastructure system; (2) each house usually has only one facade, the case for having a backyard is not the popular, so hence the requirement of microclimate is not guaranteed; (3) the need to solving the quality of living environment may lead to the growth in the use of space, the costs for facades and roof as well as the equipments for improving microclimate; (4) status quo of urban planning, architecture and landscapes reflect the dislocation, lack of uniformity and aesthetics; (5) there are difficulties in identifying urban architectural identity.

In order to solve the problem of crowded land, the decision to move into high-rise dwelling houses has considered as most feasible, even this trend has gradually become popular in urban areas. Advantages of high-rise dwelling houses are shown in following aspects:

(1) location: citizens have a variety of choices for convenient and optimal locations in terms of infrastructure;

(2) cost: buy a condominium is more reasonable than buy a townhouse;

(3) utilities: many utilities and services for living are organized according to standards and market demands;

(4) security: fire protection system and security are ensured through housing management; 
(5) health - comfort: the microclimate is better than most townhouses;

(6) supporting policy: liquidity is supported through sales policies and programs promoting the living conditions of the government.

The inadequacies of living environment, public space and microclimate in each small space of townhouses make it difficult to improve the quality of life and urban embellishment. Moreover, the environmental and energy factors in the type of individual housing can cause many disadvantages to overcome. While, the advantages of high-rise dwelling houses have been shown to represent the alternative and pioneer of revolutionary solutions for the development of housing funds and corresponding quality. Another advantage of high-rise dwelling houses is the ability to manage and operate for community groups when proposing innovative alternatives. Revolutionary solutions of design, construction and operation will be provided a foundation for linking the city's management and operation systems, creating the premise for applying the technological advances of the "smart city" concept. This will also effective in dividing the urban development phases on a predictable basis.

The interest and investment for the development of high-rise dwelling houses is considered suitable for the reality of Ho Chi Minh City.Through the diagram, it can be seen the location and role of high-rise dwelling houses in the scheme of organization and formation of a smart city.

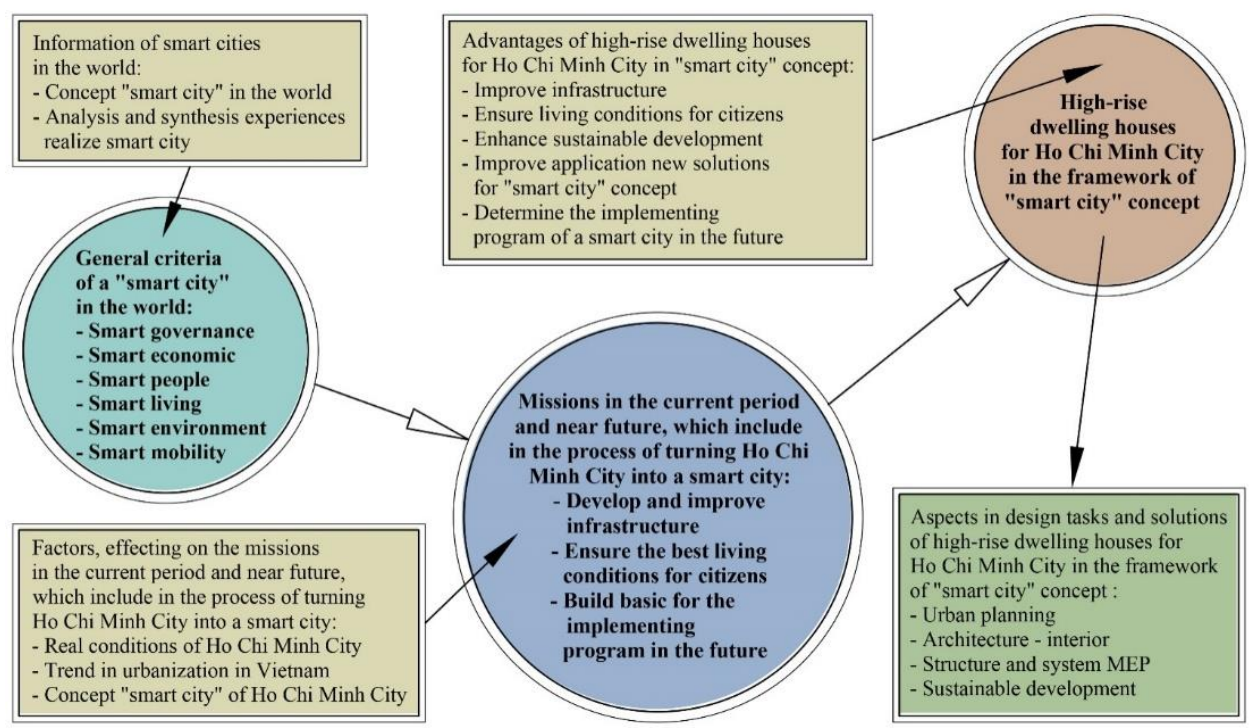

Fig. 1. Interrelated factors to access to the results of the paper.

Determining the trend in the development of high-rise dwelling houses design, serving the organization and formation Ho Chi Minh City into a smart city in the current period and near future it should follow the points of view: (1) high-rise dwelling houses need to meet requirements of smart cities on the condition that ensuring the best living conditions for citizens; (2) the overall strategy for the implementation process and the staged division should be worked out; (3) in the current period and the near future of Ho Chi Minh City the appropriate criteria must be choosen to ensure the success of the project, (4) ensuring the quality of living environment in the direction of sustainable development; (5) creating a database and a basis for connecting to the general management system of the smart infrastructure system; (6) ensuring the adaptability of the buildings in the direction of smart system in the future. 
Suggestions of this paper represent the generality of architecture and are appropriate for the type of housing project with many factors to address, especially large-scale buildings, serving for community groups. Requirements in design tasksand solutions are based on the research and experience in designing, constructing and operationof high-rise dwelling houses, especially in Ho Chi Minh City.It demonstrats the practicality of the proposals, which are based on the design experience of real projectsin Ho Chi Minh City.Results of this paperwere applied on different scales: planning, architecture - interior. In the technical aspect, solutions of structure and system MEP were considered in high level. This approach represents the synthesis of aspects of architecture: functional, technical, economical, and aesthetical.

Moreover, the cultural identity and ecological aspects of sustainable development are considered as mandatory factors. It should be noted that in the "smart city" concept the role of science and technology is vital, especially the process of management with information and the performance of various tasks will minimize direct contact. All will be more automated and useful - so that it can create challenges for the future when it comes to cultural and human factors . One of the aspects of sustainable development, which has been emphasized by designers is the need to maintain and promote traditional values in creating a unique identity for the building. The specific cultural values need to be expressed in different solutions to create a connection between the people and the living space, to be promoted the interplay between people and people in the context of modern life.

The development of high-rise dwelling houses for Ho Chi Minh City within the framework of "smart city" concept is more likely to succeed for the following reasons: (1) ensuring the social security issue and promoting the improvement of infrastructure, thus contributing to successful implementation of many criteria for a smart city; (2) the highly revolutionary of proposed solutions, which facilitate the application of many synchronous design solutions; (3) the large scale of applicationof project to the community groups; (4) the potential to bring advances of smart technology into the buildings.

This paper provides the new approach in design of high-rise dwelling houses for Ho Chi Minh City.Requirements of a better life and tendency of perfection living conditions in the direction of smart way will be ensured. This approach has potential inother criteria of "smart city" concept.

One of issues of this paper can be the fact that higher level of finacial investment for highrise dwelling houses will be enhanced more comfortable and smarter for living conditions.It could influence the realization of project in cause of real conditions in Ho Chi Minh City. However, proposed solutions can be chosen in caculation of large scale and long-term investment for groups communities. And there are various options of smart solutionsfor each holdshousewith regards to demand and ability of users. In addition, smart solutions can be upgrated and extended on the basic of suggestions in current period and near future of Ho Chi Minh City, where has been demonstrated the fast growth of standard of living.

\section{Conclusions}

Smart cities are the target of many cities in the world, where citizens are ensured the best living with all their daily activitieswill be raised to a higher and smarter level. That will provide the foundation and motivation of the whole society to pursue larger, higher and more meaningful goals. It is a modern city where people live in a comfortable, safe, intelligent and promising environment with better opportunities for future generations.

High-rise dwelling houses are designed, constructed and operated by "smart city" concept are of great significance as they play a pioneering role in organiziation and implementation of a smart city model for Ho Chi Minh City. Results of this paper are based on a strong scientific basis, expressed through specific discussion, in order to show the development 
trend of high-rise dwelling houses in the current period and near future of Ho Chi Minh City. The proposed design tasks and solutions are highly realistic, ensuring the success of determined objectives.

Results of this paper can also be applied in design of real projects for other cities of Vietnam. Specific and diverse requirements of design will stimulate other sectors to participate in the design, construction and operation of high-rise dwelling houses to improve the effectiveness of projects. Recommendations of this article canalso stimulate the basis for management and operation ofbuildings of different scales. In addition, they will provide the premise for the development and perfection of other criteria of a smart city.

\section{References}

1. Research summary. Smart cities in Italy: an opportunity in the spirit of the Renaissance for a new quality of life. ABB e The European House-Ambrosetti, 2012.

2. P.R. Patel, H.J. Padhya, Review paper for smart city. International Journal of Advance Research In Engineering, Science and Management IJARESM (2011)

3. United Nations. Smart cities anh infrastructure. Report of General Secretary. Commission on Science and Technology for Development Nineteenth session. Geneva, (2016)

4. M.F. Jawaid, S.A. Khan, International Journal of Advance Research In Science and Engineering IJARSE, 4, 990-996 (2015)

5. Center of Regianal Science (SRF). Smart cities - Ranking of European medium-sized cities. Vienna University of Technology (2007)

6. O. Parishwad, T. Singh, Journal of Civil and Environmental Technology, 1(6), 54-59 (2014)

7. A. Monzon, Smart cities concept anh challenges. Bases for the assessment of smart city projects. International Conference on Smart Cities and Green ICT Systems (SMARTGREENS) (2015)

8. K. Singh, N. Neha Sharma, International Journal in Management and Social Science IJMSS, 4 (2016)

9. Central policy unit. Research report on smart city. The government of the Hong Kong special administrative region (2015)

10. A. Caragliu, C. Del Bo, P. Nijkamp, 3rd Central European Conference in Regional Science - CERS, 1, 45-59 (2009)

11. R. Aijaz, Challenge of making smart cities in India. Asie. Visions, 87, Ifri, (2016)

12. M.H. Nguyen, http://ashui.com/mag/congnghe/xuhuong/13473-thanh-pho-thongminh-khuynh-huong-tat-yeu-hay-su-lua-chon-khon-ngoan.html (2017)

13. International Electrotechnical Commission. Smart cities. IEC, Geneva, Switzerland (2016)

14. United Nations, Department of Economic and Social Affairs. World urbanization prospects - The 2014 Revision - Highlights. New York (2014)

15. N.H. Nguyen, Vietnamese Journal of Urbanism, 26+27, 82-87 (2017)

16. Vietnam population projection 1014-2049 (Vietnam news agency publishing house, Hanoi, 2016)

17. H. Phan, http://tphcm.chinhphu.vn/xay-dung-tphem-tro-thanh- $\% \mathrm{E} 2 \% 80 \% 9$ Cthanhpho-thong-minh $\%$ E2\%80\%9D-vao-nam-2025 (2016) 
18. http://ictnews.vn/cntt/cuoc-song-thong-minh/tp-hem-co-the-tro-thanh-thanh-phothong-minh-trong-10-nam-toi-144831.ict (2016)

19. V.T. Nguyen, Development of high-rise dwellinghouses for low- and middle-income people in big cities of Vietnam (for example Ho Chi Minh City). Doctoral thesis of architecture. Saint-Petersburg State University of Architecture and Civil Engineering (2013)

20. H.L. Nguyen, Development of energy-efficient architecture in big cities of Vietnam(for example Ho Chi Minh City). Doctoral thesis of architecture. Saint-Petersburg State University of Architecture and Civil Engineering (2013)

21. J. Niu, Energy and Buildings, 36, 1259-1263 (2004)

22. E. Generalova, V. Generalov, CTBUH Journal, IV (2014)

23. H.K. Nguyen, https://www.tapchikientruc.com.vn/chuyen-muc/hinh-thuc-thiet-ke-nhacao-tang-thuc-trang-dinh-huong.html (2016)

24. V.D. Le, Architectural formation of urban dwelling houses in Vietnamwith considering the requirements of recreation of citizens. Doctoral thesis of architecture. Institute of Architecture and Arts of Southern Federal University (2010)

25. R. Kennedy, L. Buys, E. Miller, Sustainability, 7, 7741-7761 (2015)

26. T.L. Pham, http://www.baoxaydung.com.vn/news/vn/quy-hoach-kien-truc/cong-nghexanh-trong-xay-dung-giai-phap-hieu-qua-de-ung-pho-voi-bien-doi-khi-hau.html (2017)

27. A. Smith, Smith A. Building management systems (BMS). Ceminar 1 - The basics explained. A.G. Coombs Advisory. City of Melbourne (2017)

28. http://archive.vgbc.org.vn/index.php/pages/lotus-rating-tool (2017)

29. S.Hoang, https://kienviet.net/2014/10/07/infographic-5-tieu-chi-kien-truc-xanh-viet$\underline{\mathrm{nam} /}$ (2014)

30. P.L. Nguyen, http://www.nhandan.com.vn/vanhoa/nghe-doc-xem/item/25009302ngon-ngang-kien-truc-viet.html (2014)

31. P.C. Pham, Maintianing and conveying the specific values of urban architecture during expanding the existing Hochiminh City centre. Doctoral thesis of architecture. University of ArchitectureHo Chi Minh City (2015)

32. S.H.N. Nguyen, Characteristics of traditional culture exploitation in residential architecture in big cities in Vietnam. Doctoral thesis of architecture. University of Architecture Ho Chi Minh City (2016) 